\section{Visual results in children treated for retinoblastoma}

\author{
Eye (2002) 16, 115-116. DOI: $10.1038 /$
}

sj/EYE/6700071

Amblyopia is by definition a preventable cause of loss of vision. ${ }^{1,2}$ The ideal approach to managing amblyopia is to detect amblyogenic factors before the age of 2 years and prevent it through eliminating the causes of visual deprivation. ${ }^{2,3}$ Among the many factors that influence visual recovery, earlier diagnosis and treatment compliance are the most significant.

Fortunately, retinoblastoma is only a rare, although a serious cause of amblyopia. ${ }^{4}$ There are multiple mechanisms by which amblyopia can develop in the setting of retinoblastoma. These include strabismus, treatment-related complications such as radiation-induced cataracts, and macular involvement by the tumour. Therefore, it is important to realize that the risk of amblyopia exists in all phases of retinoblastoma management, that is before the treatment of retinoblastoma (diagnosis), during treatment of retinoblastoma, and even after retinoblastoma has been successfully treated. ${ }^{5}$

The main goal in retinoblastoma management is to eliminate tumor-related mortality. Preservation of the globe and visual acuity are important secondary considerations. Recent advances in the treatment of retinoblastoma have led to improved survival in developed countries with a 5-year cumulative survival rate of greater than $90 \% .6,7$ Moreover there is a trend away from enucleation. ${ }^{8}$ With the use of chemotherapy and adjuvant local therapy, fewer eyes are subjected to enucleation and radiotherapy. ${ }^{9-11}$ Published studies on the use of chemotherapy in treatment of retinoblastoma have so far emphasized the response rate and
AD Singh

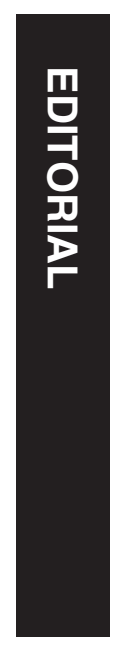

complications of treatment. ${ }^{9-13}$ There are a limited number of studies that have reported visual outcome following treatment of retinoblastoma by either radiotherapy ${ }^{14-17}$ or by chemotherapy. ${ }^{18}$

In an article published in the last issue of Eye, Watts and his associates have presented visual results in children with macular retinoblastoma who were also treated for amblyopia. ${ }^{19}$ In a selected group of 15 children with macular involvement, part-time total occlusion was performed for treatment of underlying amblyopia, depending upon the age of the child. With a median follow-up of more than 2 years, $80 \%$ of children showed improvement in vision. In 10 of 11 eyes in which $\log$ MAR acuities could be recorded, the mean difference of $0.67 \log$ MAR was statistically significant. The final acuity was $1.0 \log$ MAR or better in almost $75 \%$ of children. In these young children with maturing visual systems, the improvement in visual acuity was over and above the effect of maturation.

Although limited in impact by the design of the study (retrospective, non comparative) and the small number of cases, their findings clearly demonstrate the benefit of amblyopia treatment for children with macular retinoblastoma. Their study further supports the concept that despite the appearance of a scarred macula, the possibility of reversible functional amblyopia should always be considered. 5,14 More importantly, the study provides evidence that efforts made in salvaging eyes with macular retinoblastoma by using chemotherapy and local therapy, which requires extensive careful monitoring, are worthwhile from a visual standpoint because the final acuity was $1.0 \log$ MAR or better in almost $75 \%$ of children.

\section{References}

1 Attebo K, Mitchell P, Cumming R, Smith W, Jolly N, Sparkes R. Prevalence and causes of amblyopia in an adult population. Ophthalmology 1998; 105: 154-159.
Wills Eye Hospital Thomas Jefferson University Philadelphia PA, USA

Correspondence: AD Singh MD Department of Ophthalmology Royal Hallamshire Hospital Glossop Road Sheffield, S10 2JF, UK Tel: 441142712902 Fax: 441142766381 E-mail: Arunsingh@ Eyetumors.com 
2 Campos E. Amblyopia. Surv Ophthalmol 1995; 40: 23-39.

3 Gottlob I. The detection, prevention, and rehabilitation of amblyopia. Curr Opin Ophthalmol 1999; 10: 300-304.

4 Magramm I. Amblyopia: etiology, detection, and treatment. Pediatr Rev 1992; 13: 7-14.

5 Kushner BJ. Functional amblyopia associated with organic ocular disease. Am J Ophthalmol 1981; 91: 39-45.

6 Tamboli A, Podgor MJ, Horm JW. The incidence of retinoblastoma in the United States: 1974 through 1985. Arch Ophthalmol 1990; 108: 128-132.

7 Sanders BM, Draper GJ, Kingston JE. Retinoblastoma in Great Britain 1969-80: incidence, treatment, and survival. Br J Ophthalmol 1988; 72: 576-583.

8 Shields JA, Shields CL, Sivalingam V. Decreasing frequency of enucleation in patients with retinoblastoma. Am J Ophthalmol 1989; 108: 185-188.

9 Murphree AL, Villablanca JG, Deegan WF, Sato JK, Malogolowkin M, Fisher A et al. Chemotherapy plus local treatment in the management of intraocular retinoblastoma. Arch Ophthalmol 1996; 114: 1348-1356.

10 Gallie BL, Budning A, DeBoer G, Thiessen JJ, Koren G, Verjee $\mathrm{Z}$ et al. Chemotherapy with focal therapy can cure intraocular retinoblastoma without radiotherapy. Arch Ophthalmol 1996; 114: 1321-1328.

11 Kingston JE, Hungerford JL, Madreperla SA, Plowman PN. Results of combined chemotherapy and radiotherapy for advanced intraocular retinoblastoma. Arch Ophthalmol 1996; 114: 1339-1343.
12 Friedman DL, Himelstein B, Shields CL, Shields JA Needle M, Miller D et al. Chemoreduction and local ophthalmic therapy for intraocular retinoblastoma. J Clin Oncol 2000; 18: 12-17.

13 Benz MS, Scott UI, Murray TG, Kramer D, Toledano S. Complications of systemic chemotherapy as treatment of retinoblastoma. Arch Ophthalmol 2000; 118: 577-578.

14 Hall LS, Ceisler E, Abramson DH. Visual outcomes in children with bilateral retinoblastoma. AAPOS 1999; 3: 138-142.

15 Holbek S, Ehlers N. Long-term visual results in eyes cured for retinoblastoma by radiation. Acta Ophthalmologica 1989; 67: 560-566.

16 Lam BL, Judisch GF, Sobol WM, Blodi CF. Visual prognosis in macular retinoblastomas. Am J Ophthalmol 1999; 110: 229-232.

17 Weiss AH, Karr DJ, Kalina RE, Lindsley KL, Pendergrass TW. Visual outcomes of macular retinoblastoma after external beam radiation therapy. Ophthalmology 1994; 101: 1244-1249.

18 Lueder GT, Goyal R. Visual function after laser hyperthermia and chemotherapy for macular retinobalstoma. Am J Ophthalmol 1996; 121: 582-584.

19 Watts P, Westall C, Colpa L, Mackeen L, Abdolell M, Gallie B, Heon E. Visual results in children treated for macular retinoblastoma. Eye 2002; 16: 75-80. 